\title{
Binding communication to improve peripheral venous catheter monitoring
}

Thibaut Albertini ${ }^{1}$, OLGA FLOREA BODEAN ${ }^{1}$, Fanyu HUANG ${ }^{1}$, Jeremy Gonin ${ }^{1}$, Jean Gaudart $^{2}$, Sophia Boudjema ${ }^{1}$, Isabelle Richer ${ }^{1}$, Celine Pascual-Espuny ${ }^{3}$, Michel Durampart $^{3}$, and Philippe Brouqui ${ }^{1}$

${ }^{1}$ IHU Méditerranée Infection

${ }^{2}$ Aix Marseille Univ, AP-HM, INSERM, IRD, SESSTIM, Hop Timone, BioSTIC, Biostatistics \& ICT

${ }^{3}$ Mediterranean Institute for Information and Communication Science

April 27, 2021

\begin{abstract}
Background: Optimizing the monitoring of peripheral venous catheters is essential. We developed a nursing record system at bedside (Patient Smart Reader $囚$ ) to track peripheral venous catheters acts. Aims: Improve peripheral venous catheter monitoring. To improve the quality of monitoring, we aimed to increase the usage rate of nursing record system at bedside. Methods: We developed a "commitment intervention" course based on binding communication paradigm. Evaluation of its performance on monitoring was analyzed using a p-chart and time series analysis. Findings: Nurses observed a significant improvement in compliance with catheter monitoring over time (shifts after shifts), ranging from 27.6\% $(\mathrm{CI}=[25.3 ; 30.0]$ ) of compliance before commitment intervention to $47.4 \%(\mathrm{CI}=[45.0 ; 49.9])$ after training. The commitment intervention increased the chances of carrying out monitoring through the tool for acts related to peripheral venous catheter by 2.42 (odds ratio) (CI $=[1.88 ; 3.11])$. Conclusion: Binding communication provides an effective method for changing nurses' behaviors in terms of safe care. The determinants of engagement (individual vs. collective) can be indicators for defining future communication and training strategies in care centers for all Health care workers.
\end{abstract}

\section{Hosted file}

Manuscript.pdf available at https://authorea.com/users/410451/articles/519834-bindingcommunication-to-improve-peripheral-venous-catheter-monitoring

Hosted file

Table.pdf available at https://authorea.com/users/410451/articles/519834-bindingcommunication-to-improve-peripheral-venous-catheter-monitoring

\section{Hosted file}

Figure Legends.pdf available at https://authorea.com/users/410451/articles/519834-bindingcommunication-to-improve-peripheral-venous-catheter-monitoring 

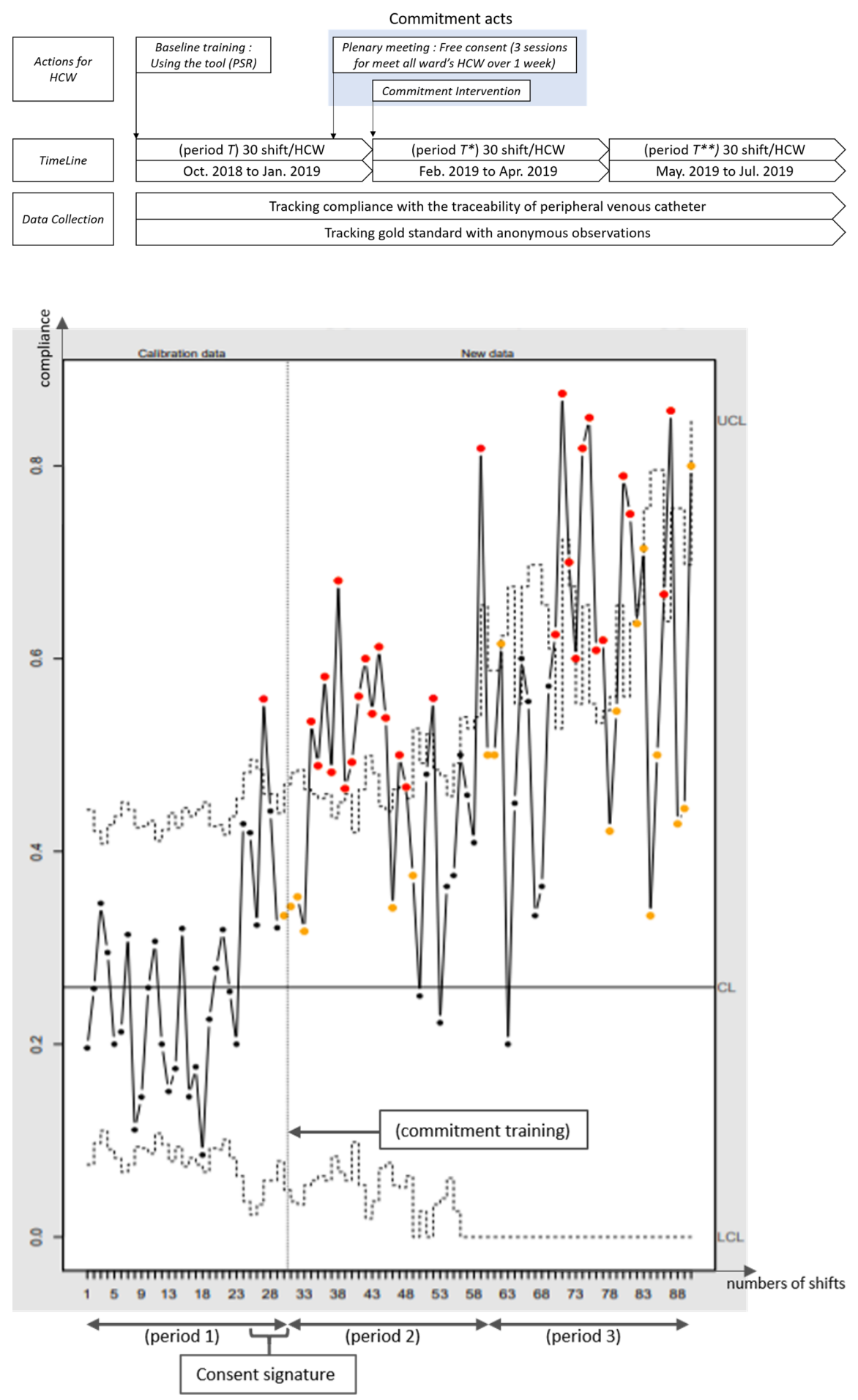